\title{
Identification and characterization of the ergochrome gene cluster in the plant pathogenic fungus Claviceps purpurea
}

\author{
Lisa Neubauer ${ }^{1 \dagger}$, Julian Dopstadt ${ }^{2 \dagger}$, Hans-Ulrich Humpf $^{2}$ and Paul Tudzynski ${ }^{*}$
}

\begin{abstract}
Background: Claviceps purpurea is a phytopathogenic fungus infecting a broad range of grasses including economically important cereal crop plants. The infection cycle ends with the formation of the typical purple-black pigmented sclerotia containing the toxic ergot alkaloids. Besides these ergot alkaloids little is known about the secondary metabolism of the fungus. Red anthraquinone derivatives and yellow xanthone dimers (ergochromes) have been isolated from sclerotia and described as ergot pigments, but the corresponding gene cluster has remained unknown. Fungal pigments gain increasing interest for example as environmentally friendly alternatives to existing dyes. Furthermore, several pigments show biological activities and may have some pharmaceutical value.
\end{abstract}

Results: This study identified the gene cluster responsible for the synthesis of the ergot pigments. Overexpression of the cluster-specific transcription factor led to activation of the gene cluster and to the production of several known ergot pigments. Knock out of the cluster key enzyme, a nonreducing polyketide synthase, clearly showed that this cluster is responsible for the production of red anthraquinones as well as yellow ergochromes. Furthermore, a tentative biosynthetic pathway for the ergot pigments is proposed. By changing the culture conditions, pigment production was activated in axenic culture so that high concentration of phosphate and low concentration of sucrose induced pigment syntheses.

Conclusions: This is the first functional analysis of a secondary metabolite gene cluster in the ergot fungus besides that for the classical ergot alkaloids. We demonstrated that this gene cluster is responsible for the typical purple-black color of the ergot sclerotia and showed that the red and yellow ergot pigments are products of the same biosynthetic pathway. Activation of the gene cluster in axenic culture opened up new possibilities for biotechnological applications like the dye production or the development of new pharmaceuticals.

Keywords: Claviceps purpurea, Secondary metabolism, Biosynthesis, Gene cluster, Ergot pigments, Ergochromes, Anthraquinones, Nonreducing polyketide synthase

\section{Background}

The biotrophic ascomycete Claviceps purpurea infects a broad range of grasses including economically important cereal crop plants like rye, wheat and barley [1]. The fungus infects exclusively the young ovaries of the host plants. After successful colonization the ovary is replaced

\footnotetext{
*Correspondence: tudzyns@uni-muenster.de

${ }^{\dagger}$ Lisa Neubauer and Julian Dopstadt contributed equally to this work

${ }^{1}$ Institute of Plant Biology and Biotechnology, Westfälische Wilhelms-

Universität Münster, Schlossplatz 8, 48143 Münster, Germany

Full list of author information is available at the end of the article
}

by fungal mycelium and production of conidia begins. The infection cycle ends with the formation of a sclerotium, the resting structure of the fungus [2, 3]. Ergot alkaloids, the best characterized secondary metabolites of $C$. purpurea, are produced exclusively in the sclerotial tissue. These toxins are historically important as they affect the central nervous system of mammalians and were the reason for severe intoxications in the past, caused by consumption of contaminated bread [4]. Sclerotia are shaped like a grain but are usually larger $(2-25 \mathrm{~mm})$ and the hard outer cortex is pigmented purple-black. Sclerotia contain 
$1-2 \%(w / w)$ of pigments belonging to different structural groups [5].

The red pigments endocrocin and clavorubin (Fig. 1) are anthraquinone derivatives [6]. Both are hydroxyanthraquinonecarboxylic acids and differ only in one hydroxy group. Clavorubin is red whereas endocrocin has an orange-red color.

The yellow ergochromes are dimers of tetrahydroxanthone units [7]. Four different xanthone derivatives were described as ergochrome units in C. purpurea and all possible combinations of two of these units occur in nature [8]. Their concentration in the sclerotia is considerably higher $(5 \mathrm{~g} / \mathrm{kg})$ than that of endocrocin and clavorubin $(40 \mathrm{mg} / \mathrm{kg})$ [8]. Ergochromes are known for their biological activity. Many of them show anti-inflammatory, cytostatic and anti-tumor activity or a neuroprotective effect [9-11]. Due to the structural similarity of the ergochromes to the anthraquinone pigments (Fig. 1) it is likely that both pigments are products of the same biosynthetic pathway. In Aspergillus nidulans it has already been shown that endocrocin is a shunt product during the production of xanthones [12, 13]. Nevertheless, the biosynthesis of the ergochromes in C. purpurea remains unclear, although some intermediates like emodin have been described [8].<smiles>Cc1cc2c(c(O)c1C(=O)O)C(=O)c1cc(O)cc(O)c1C2=O</smiles><smiles>Cc1cc2c(c(O)c1C(=O)O)C(=O)c1c(O)cc(O)c(O)c1C2=O</smiles>

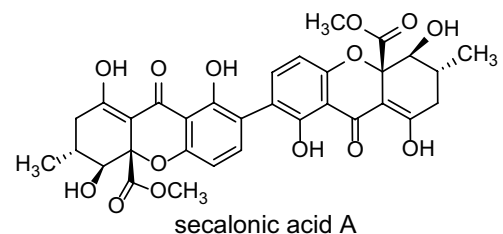

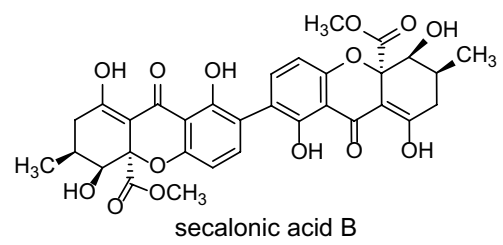

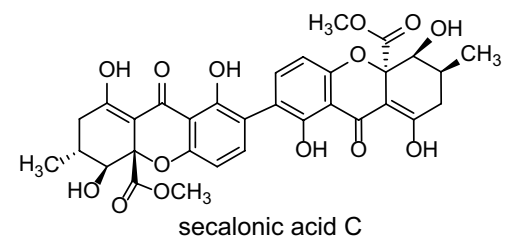

Fig. 1 Ergot pigments. Endocrocin and clavorubin are red hydroxyanthraquinonecarboxylic acids. Secalonic acids A, B and C belong to the group of yellow ergochromes
Endocrocin could be identified in extracts of various other fungi [14-16] but its biosynthesis is best characterized in Aspergillus fumigatus where a cluster of four genes has been identified [17]. The key enzyme of the cluster is a nonreducing polyketide synthases (NR-PKS) lacking the thioesterase (TE) domain usually necessary for releasing the polyketide product from the enzyme. In these special types of NR-PKSs the polyketide is released from the PKS by a metallo- $\beta$-lactamase-type thioesterase (MßL-TE) [18]. Recently, in A. fumigatus a second gene cluster has been identified which also contributes to the formation of endocrocin as a shunt product from production of the anthraquinone-derivative trypacidin [19]. Both clusters show homologies to clusters responsible for the formation of related anthraquinone-derivatives such as geodin in Aspergillus terreus [20] and the xanthones in A. nidulans $[12,13]$.

This paper reports the identification of a gene cluster in C. purpurea which shows high homology to these gene clusters and is involved in ergochrome biosynthesis. Besides the classical ergot alkaloid cluster, this is the first functional analysis of a secondary metabolite gene cluster in the ergot fungus.

\section{Results}

\section{Characteristics of the gene cluster}

Bioinformatic analysis of the C. purpurea genome revealed the presence of three nonreducing polyketide synthases [21]. In a phylogenetic tree CPUR_05437 groups with NR-PKSs of the $A$. terreus geodin cluster (GedC) [20], the A. fumigatus trypacidin (TpcC) [19] and endocrocin (EncA) [17] clusters and the A. nidulans monodictyphenone cluster (MdpG) [12] (Fig. 2a). Analysis of the domain structure of this protein, using the NCBI Conserved Domain Database, shows that CPUR_05437 also belongs to the group of TE-less PKSs (Fig. 2b) and the genes surrounding CPUR_05437 (Fig. 2c) have significant identity to the genes of the endocrocin, monodictyphenone, trypacidin, and geodin biosynthetic clusters (Table 1). Particularly the genes probably encoding enzymes necessary for the formation of endocrocin are present in the $C$. purpurea cluster, for example the MBL-TE type hydrolase CPUR_05436 and the decarboxylase CPUR_05435. Homologs to other genes involved in biosynthesis of monodictyphenone, trypacidin, or geodin are also located in the $C$. purpurea gene cluster. However, for some genes no homolog could be identified in $C$. purpurea, and three genes (CPUR_05425, CPUR_05426, CPUR_05431) appear to be Claviceps specific.

\section{In planta expression}

To check if the gene cluster is responsible for the typical pigment formation of $C$. purpurea, we first tested if 


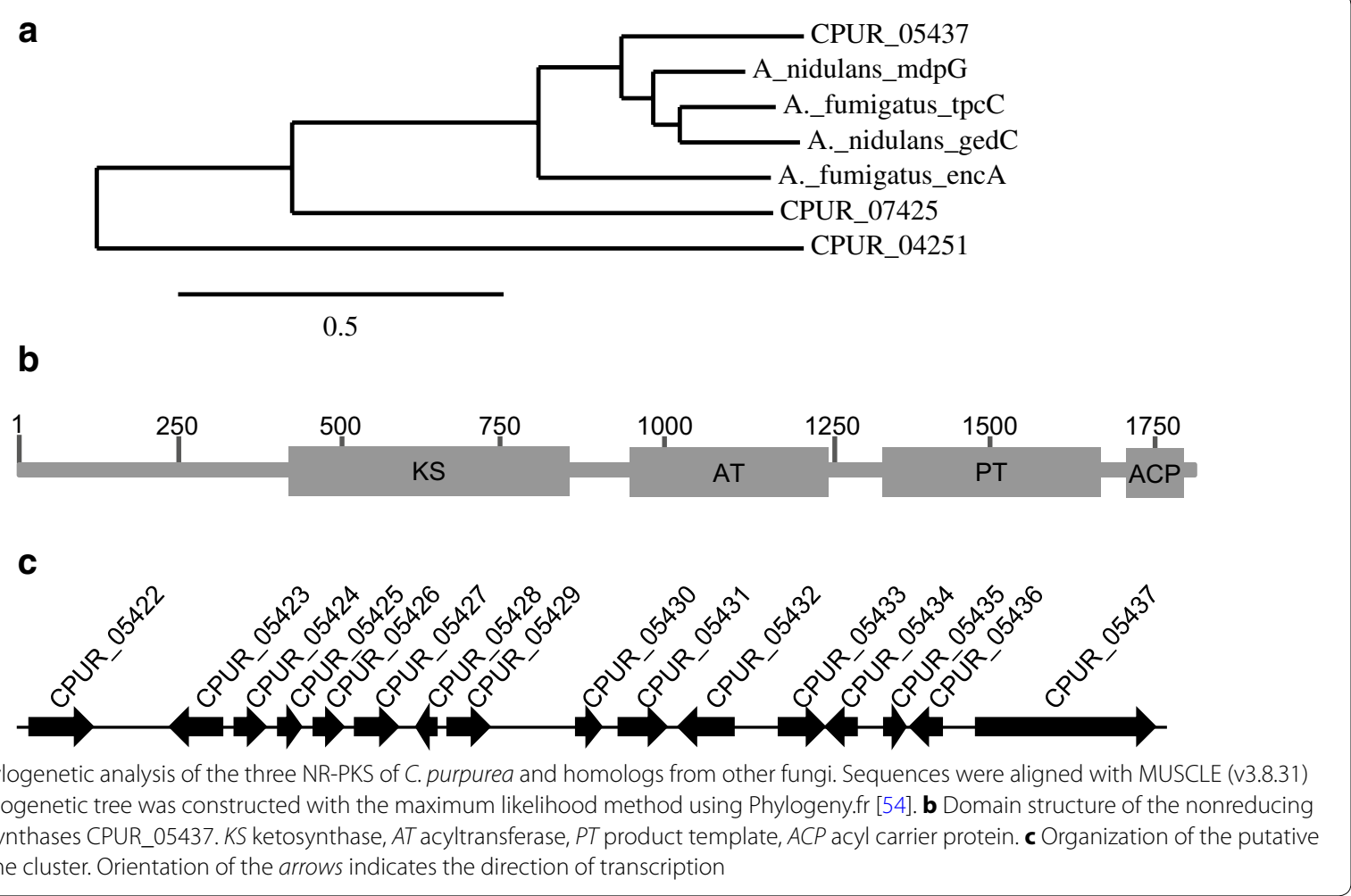

the expression of a central cluster gene (CPUR_05436) is correlated with the pigmentation in planta. Therefore, rye plants were infected with the $C$. purpurea wild type strain Ecc93 and the relative expression of CPUR_05436 was quantified via quantitative reverse-transcription PCR (qRT-PCR) 5, 10, 15 and 20 days post-infection (dpi). Detectable gene expression starts $10 \mathrm{dpi}$ and shows an increase towards the late stages of infection (Fig. 3). A correlation with the formation of the sclerotia and thus the pigment production could be observed. Although the results show high variability due to the heterogenous biological material (the infection process cannot be completely synchronized), this tendency was consistent with results from three biological replicates.

\section{Gene expression in axenic culture and optimization of the culture conditions}

Under standard laboratory conditions, using liquid cultures with BII complex medium, the gene cluster was not expressed and no coloration of the culture broth was visible. By using a defined medium with different sucrose concentrations $(100,200,300 \mathrm{~g} / \mathrm{L})$, the gene cluster became activated in the cultures with a low sucrose concentration of $100 \mathrm{~g} / \mathrm{L}$. After 10 days of cultivation first signs of pigmentation occurred and after 14 days red pigmentation of the culture became evident. Additional variation in phosphate by adding different amounts of
$\mathrm{KH}_{2} \mathrm{PO}_{4}$ led to marked pigmentation of the cultures at the lower concentration of sucrose (100 or $200 \mathrm{~g} / \mathrm{L})$ and the higher concentration of phosphate $\left(4 \mathrm{~g} / \mathrm{L} \mathrm{KH_{2 }} \mathrm{PO}_{4}\right)$ already after 10 days of cultivation (Fig. 4). As shown by northern blot analysis (Fig. 5a), the pigment formation correlates in a qualitative sense with the expression of the predicted cluster genes CPUR_05423 to CPUR_05437. Genes CPUR_05422 and CPUR_05438 are not co-regulated with the cluster genes, confirming the borders of the gene cluster. Taken together, there is an inverse influence of sucrose and phosphate concentration on pigment expression and an activation of the pigment production in axenic culture is possible by supplying high amounts of phosphate in combination with low sucrose concentrations.

\section{Overexpression of the transcription factor and the PKS}

To verify if the PKS CPUR_05437 gene cluster is responsible for the pigment synthesis in C. purpurea we overexpressed the $\mathrm{Zn}_{2} \mathrm{Cys}_{6}$ transcription factor CPUR_05433 by introducing an additional copy under the control of the strong constitutive $A$. nidulans oliC (mitochondrial ATP synthase subunit 9 gene) promoter (Additional file 1: Figure S1A). For three independent transformants the overexpression of the transcription factor as well as of nine further cluster genes could be confirmed by northern blot analyses (Fig. 5b). These results show that 
Table 1 Predicted functions and homologs of the pigment gene cluster in C. purpurea

\begin{tabular}{|c|c|c|c|c|c|}
\hline C. purpurea & Enc & MDP & Tpc & Ged & Predicted function \\
\hline CPUR_05423 & - & $m d p D$ & - & - & Monooxygenase \\
\hline CPUR_05424 & - & - & $\operatorname{tpcM}$ & $\operatorname{ged} G$ & Methyltransferase \\
\hline CPUR_05425 & - & - & - & - & $?$ \\
\hline CPUR_05426 & - & - & - & - & $?$ \\
\hline CPUR_05427 & - & $m d p L$ & $\operatorname{tpcl}$ & gedk & Oxidase \\
\hline CPUR_05428 & - & $m d p B$ & - & - & Dehydratase \\
\hline CPUR_05429 & - & $m d p C$ & - & - & Reductase \\
\hline CPUR_05430 & - & $m d p K$ & $\operatorname{tpc} G$ & gedF & Oxidoreductase \\
\hline CPUR_05431 & - & - & - & - & Monooxygenase \\
\hline CPUR_05432 & - & $m d p A$ & $\operatorname{tpcD}$ & $\operatorname{ged} D$ & Coactivator \\
\hline CPUR_05433 & - & $m d p E$ & $\operatorname{tpcE}$ & $\operatorname{ged} R$ & Transcription factor \\
\hline CPUR_05434 & - & $m d p H$ & $\operatorname{tpcL}$ & gedH & Decarboxylase \\
\hline CPUR_05435 & encC & $m d p H$ & tpck & gedl & Decarboxylase \\
\hline CPUR_05436 & $e n c B$ & $m d p F$ & $\operatorname{tpc} B$ & $\operatorname{ged} B$ & Hydrolase \\
\hline CPUR_05437 & encA & $m d p G$ & $\operatorname{tpcC}$ & $\operatorname{ged} C$ & Non-reducing PKS \\
\hline- & - & mdpl & - & - & Acyl-CoA synthase \\
\hline- & - & mdp」 & $\operatorname{tpcF}$ & gedE & Glutathione S-transferase \\
\hline- & - & - & $\operatorname{tpc} A$ & $\operatorname{ged} A$ & O-Methyltransferase \\
\hline- & - & - & $t p c\rfloor$ & ged」 & Dihydrogeodin oxidase \\
\hline- & - & - & - & gedL & Sulochrin halogenase \\
\hline- & - & - & $\operatorname{tpcH}$ & - & Methyltransferase \\
\hline
\end{tabular}

Enc endocrocin A. fumigatus [17], MDP monodictyphenone A. nidulans [12], TpC Trypacidin A. fumigatus [19], Ged Geodin A. terreus [20]

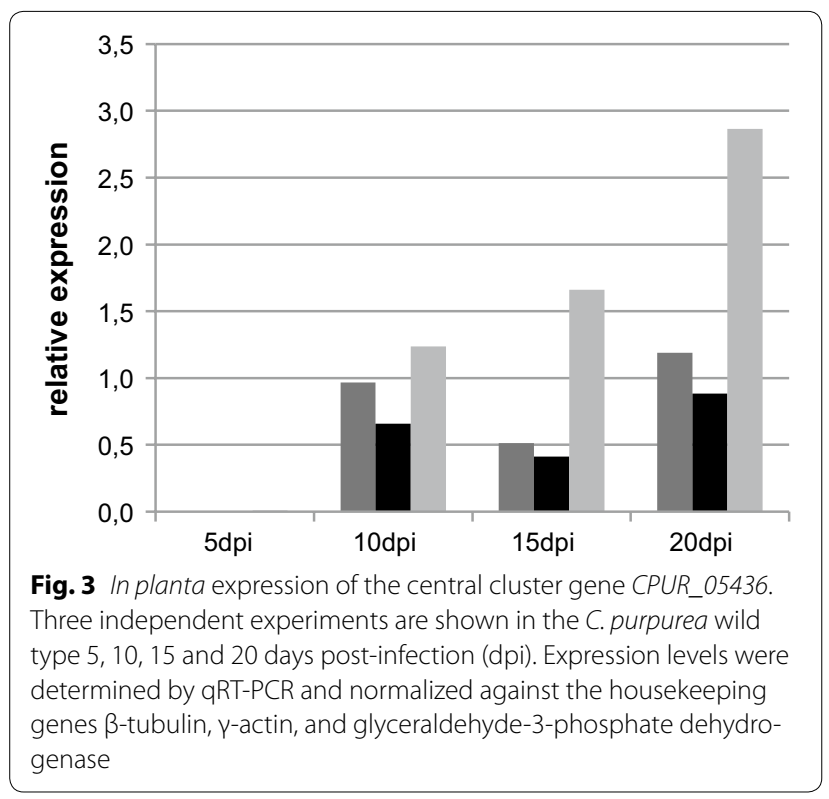

the genes CPUR_05425, CPUR_05426, CPUR_05427, CPUR_05428, CPUR_05429, CPUR_05434, CPUR_05435, CPUR_05436, as well as CPUR_05437 are regulated by CPUR_05433. As expression of the other cluster genes is very low, the co-regulation by the transcription factor could not be confirmed by northern analyses.

Nevertheless, the transcription factor overexpression mutants (OE TF) show a clear orange-red pigmentation, also under growth conditions unfavorable for pigment production (Fig. 6). To analyze the products of the gene cluster, pigments were extracted from fungal mycelia and the metabolite profile of the wild type and OE TF mutants was compared using reverse-phase-high-performance liquid chromatography-diode-array detection-high resolution mass spectrometry (RP-HPLC-DAD-HRMS). Identification of the pigments was based on three parameters, the characteristic UV-spectra [16, 22], the exact mass $( \pm 1.5 \mathrm{ppm})$ and subsequent HMRS $^{\mathrm{n}}$ experiments. The latter were compared to already described fragments in the literature $[12,16]$.

In the $\mathrm{OE} \mathrm{TF}$ cultures the red pigments endocrocin and clavorubin could be detected as well as prominent signals of the yellow ergochrome secalonic acid. Figure 7 clearly demonstrates difference in yellow pigment signals at UV $332 \mathrm{~nm}$ between the OE TF and the wild type. The marked signals at 34, 35 and $36 \mathrm{~min}$ correspond to a $\mathrm{m} / \mathrm{z}$ value of 637.1554 , matching closely to the theoretical mass 637.1561 for secalonic acid derivatives in the negative ionization mode. Furthermore, typical losses of water $(m / z 619)$, a methoxy-group $(m / z 605)$ and an add-on loss of $\mathrm{CO}_{2}(\mathrm{~m} / z$ 577) were obvious in the MS/MS spectra (Fig. 8). Unfortunately, the obtained information is insufficient to determine the specific derivate, as no references are commercially available. Nevertheless, three signals with the same UV spectra, exact mass and characteristic and synchronic MS/MS spectra correspond to all three different ergochromes.

To search for anthraquinone derivatives, the DAD spectra were screened in the unique absorbance region of $440-480 \mathrm{~nm}$ for red pigments. The detailed UV spectra of the substances with a retention time of 21.8 and $22.8 \mathrm{~min}$ (Fig. 9a) strongly showed the characteristic absorbance maxima for endocrocin at a retention time of $21.8 \mathrm{~min}$ (Fig. 10a) as well as clavorubin at a retention time of $22.8 \mathrm{~min}$ (Fig. 10b) and therefore provided evidence for their occurrence. The UV signal itself is a compelling indicator of clavorubin as the principal anthraquinone metabolite with a much higher peak intensity compared to endocrocin. HRMS also unambiguously identified the peaks by comparing the experimental $(313.0350$ and 329.0301) and theoretical $m / z$ values (313.0352 and 329.0301). The MS/MS experiments (Fig. 10d, e) additionally illustrated typical neutral losses of $\mathrm{CO}_{2}$ or water. In previous studies [23] those fragments were revealed as the most dominant and characteristic fragments for 


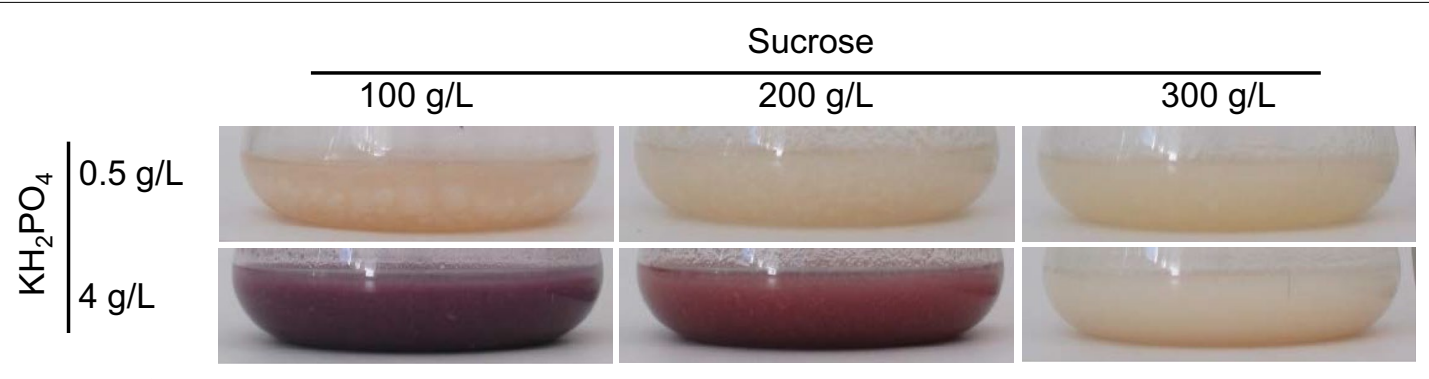

Fig. 4 Optimization of the culture conditions. Pigmentation of C. purpurea liquid cultures depends on the sucrose and phosphate concentration. Cultures were grown for 10 days

phenolic compounds, especially in the negative ionization mode.

To get further insight into the biosynthesis of the pigments, a strain where only the PKS CPUR_05437 is overexpressed (OE PKS) was generated (Additional file 1: Figure S1B). Overexpression of the gene was confirmed by northern blot analyses (Additional file 1: Figure S1C) and the strain was cultured under growth conditions unfavorable for the pigment production. After 7 days of cultivation the culture was clearly pigmented. However, in contrast to the OE TF cultures the color was more purple red (Fig. 6). The UV signal of clavorubin at $22.8 \mathrm{~min}$ in Fig. 9 highlights the considerable production of the red pigments in the OE PKS strain (Fig. 9b) compared to the wild type (Fig. 9a). The UV intensity indicates an approximately 10 times higher production of clavorubin in the OE PKS mutant compared to the wild type and a two times greater production compared to the OE TF. In addition, Fig. 9d, e illustrates the increased mass spectrometric signal intensity of endocrocin, as well also of clavorubin, between the wild type and the OE PKS mutant.

Taken together, chemical analyses of the OE TF and the OE PKS cultures clearly show that activation of the whole cluster primarily leads to increased production of the yellow ergochrome dimers, whereas overexpression of the PKS merely increases occurrence of red anthraquinones.

\section{PKS CPUR_05437 is responsible for pigmentation in axenic culture and in planta}

Finally to prove that the PKS CPUR_05437 is the key enzyme in the pigment biosynthesis in C. purpurea, the corresponding gene was knocked out. Replacement of the gene by a phleomycin resistance cassette was verified by diagnostic PCR and Southern blot analysis (Additional file 2: Figure S2). Two independent knock out mutants as well as the C. purpurea wild type were grown in liquid media favorable for the pigment production $(100 \mathrm{~g} / \mathrm{L}$ sucrose and $4 \mathrm{~g} / \mathrm{L} \mathrm{KH}_{2} \mathrm{PO}_{4}$ ). After 10 days of cultivation the wild type culture had dark purple red pigmentation, whereas the cultures of the knock out mutants remained colorless (Fig. 11a).

To verify the visible impressions, the metabolite profiles of both strains were compared using RP-HPLCDAD-HRMS. In the wild type cultures the red pigments endocrocin and clavorubin as well as the yellow secalonic acids were detected (Fig. 12a). In the cultures of the knock out mutants neither the red nor the yellow pigments were detectable in the DAD spectra (Fig. 12b) or in HRMS measurements (Fig. 12c-e).

To show that the PKS is also responsible for the typical pigmentation of the ergot sclerotia in planta, rye plants were infected with the C. purpurea wild type as well as the PKS knock out mutants. The pathogenicity assay shows that the mutants were able to infect the plants normally. First signs of successful infection (honeydew production) were evident 7-8 days post-inoculation. Approximately 15 days post-inoculation sclerotia were visible. After about 3 weeks the sclerotia of the wild type were pigmented purple black. In contrast, sclerotia of the $\triangle$ PKS mutants were colorless (Fig. 11b). Notably, sclerotia of all groups were of similar size and consistency. Complementation of the knock out with a PKS overexpression construct restored the pigmentation in axenic culture as well as in planta (Additional file 3: Figure S3).

Taken together the results clearly show that the PKS CPUR_5437 gene cluster is responsible for the formation of both kinds of ergot pigments; this applies both to the red anthraquinones and to the yellow ergochromes which are more complex xanthone derivatives.

\section{Discussion}

Pigments are produced by a variety of filamentous fungi. In Aspergillus flavus or Alternaria alternata, for example, pigments such as melanin and asparasone play a protective role against abiotic stresses, e.g. UV radiation [24, 25]. In other fungi like the human pathogen A. fumigatus and the plant pathogen Magnaporthe oryzae melanin is required for virulence [26]. Pigmentation is often 


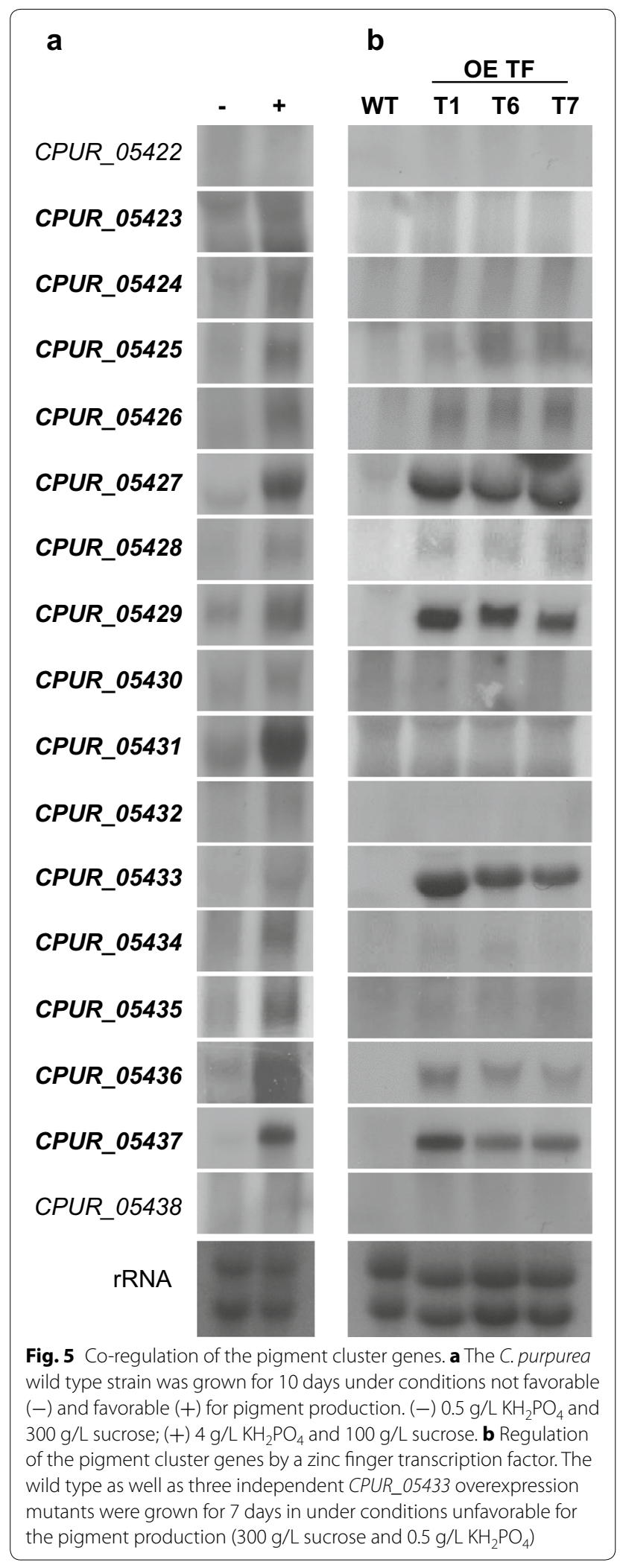

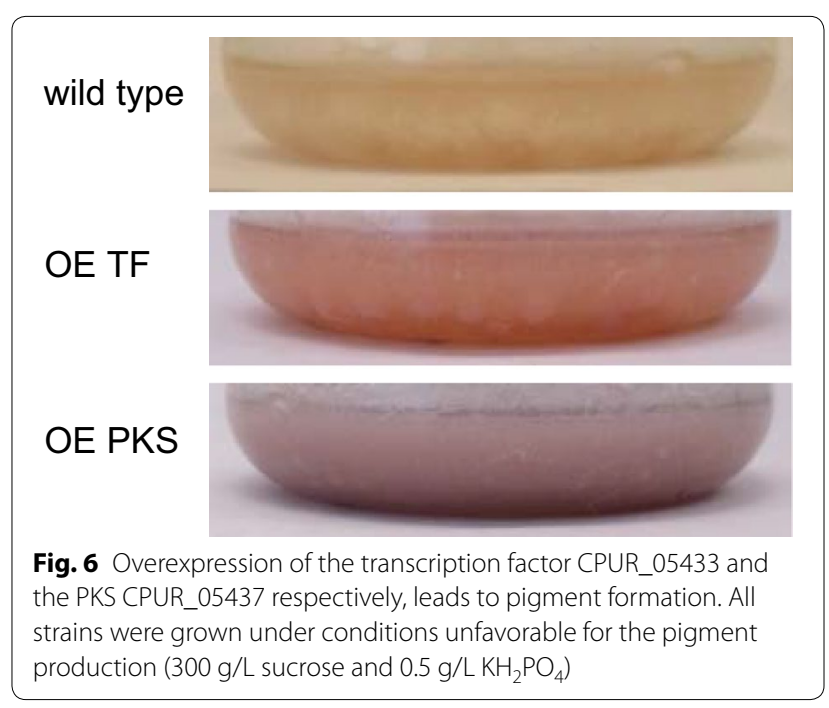

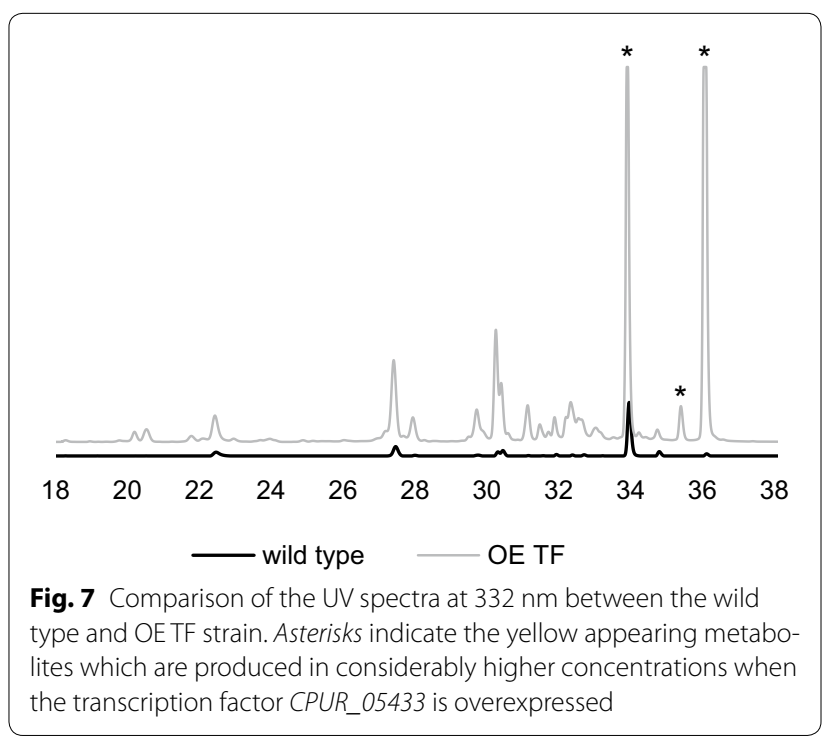

associated with developmental structures like spores or sclerotia. C. purpurea produces pigments mainly in the sclerotia. Sclerotia are resting structures and thus there is a strong requirement for them to be able to overcome biotic and abiotic stresses over a longer period in the field. Sclerotia of A. flavus asparasone minus mutants, for example, were significantly less resistant to insect predation and more susceptible to ultraviolet light and heat [25]. According to the reported functions of pigments in other fungi, it could be assumed that the ergot pigments are also important for the survival of the $C$. 


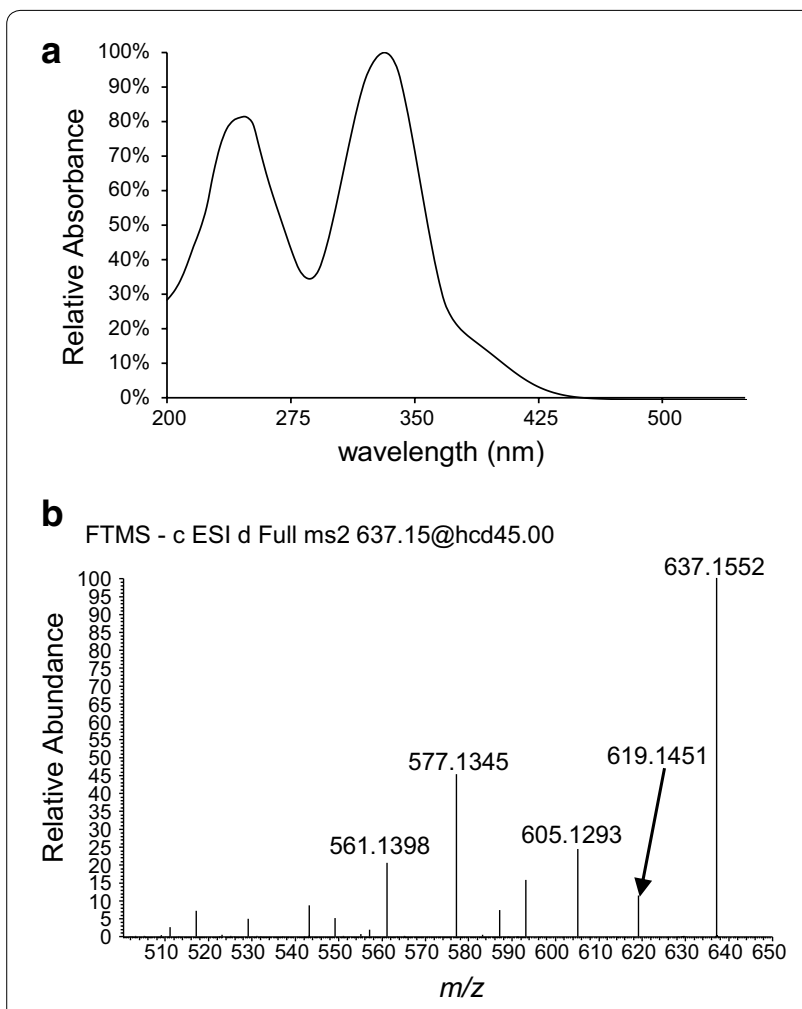

Fig. 8 Characteristic UV (a) and MS/MS (b) spectra of the identified secalonic acid derivatives in the OE TF strain

purpurea sclerotia. However, there is no difference in the consistency of the albino sclerotia in comparison to the wild type assuming that they are not more sensitive to mechanical damage. Interestingly, it has been shown that knock out of members of the NADPH oxidase (Nox) complex, usually involved in infection processes of pathogenic fungi, leads to the formation of white but small and immature pseudosclerotia in C. purpurea [27, 28]. qRT-PCR revealed a reduced PKS Cpur_05437 gene expression in the $\Delta c p n o x 2$ sclerotia [28] showing the complexity of pathogenic development and secondary metabolism in C. purpurea. Furthermore, the formation of the ergot pigments is contemporary with ergot alkaloid synthesis in planta. As the ergot alkaloids are light sensitive, pigmentation of the sclerotia is important for the protection of these toxins [29]. Surprisingly, in axenic culture, the expression of the pigment cluster and the alkaloid cluster are regulated contrary. While for the alkaloid production low levels of phosphate and a high sucrose concentration are necessary, the pigment production is increased by high levels of phosphate and repressed by high levels of sucrose. Apparently, there are different signaling pathways regulating the secondary metabolite production in planta and in axenic culture.

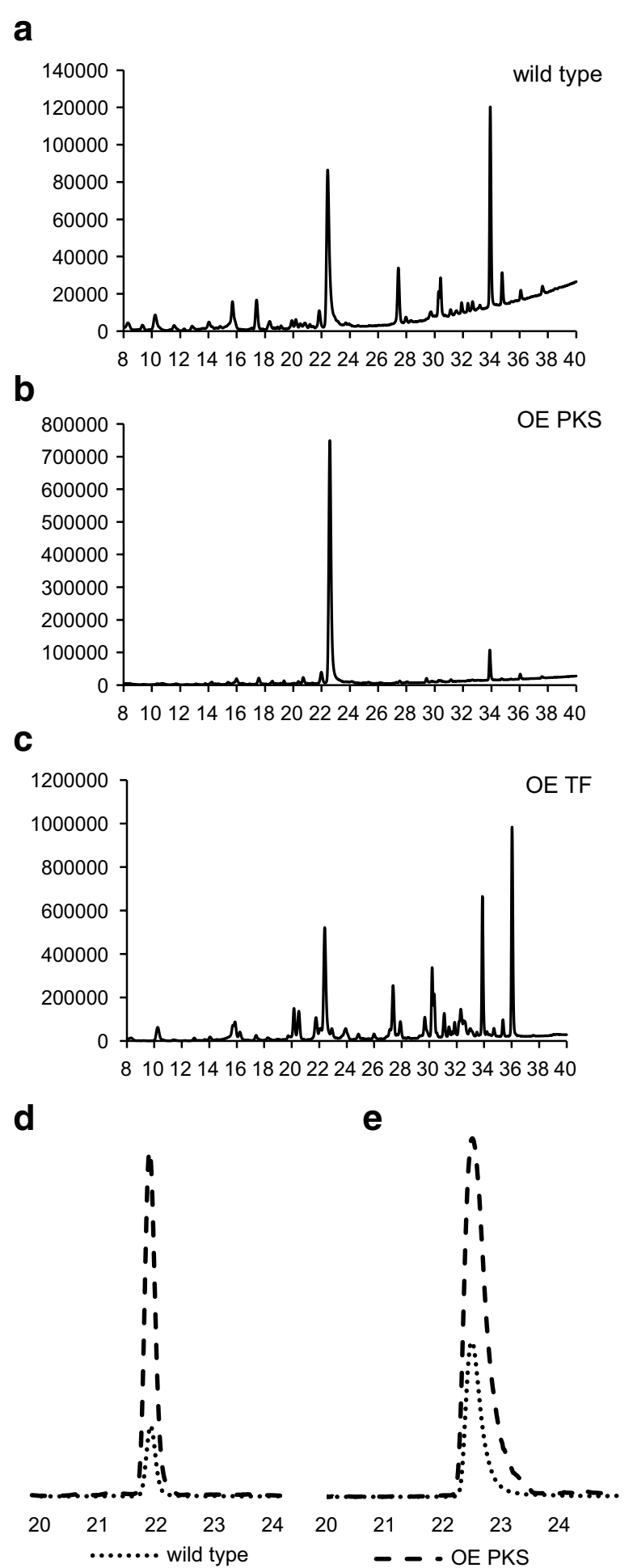

Fig. 9 HPLC-DAD profiles of the wild type (a), the OE PKS (b) and the OE TF (c) as well as the HPLC-MS profile comparison of endocrocin (d) and clavorubin (e) between the wild type and OE PKS strain. Strains were grown under conditions unfavorable for the pigment production. The relative difference between the mass spectrometric signal intensity is represented 


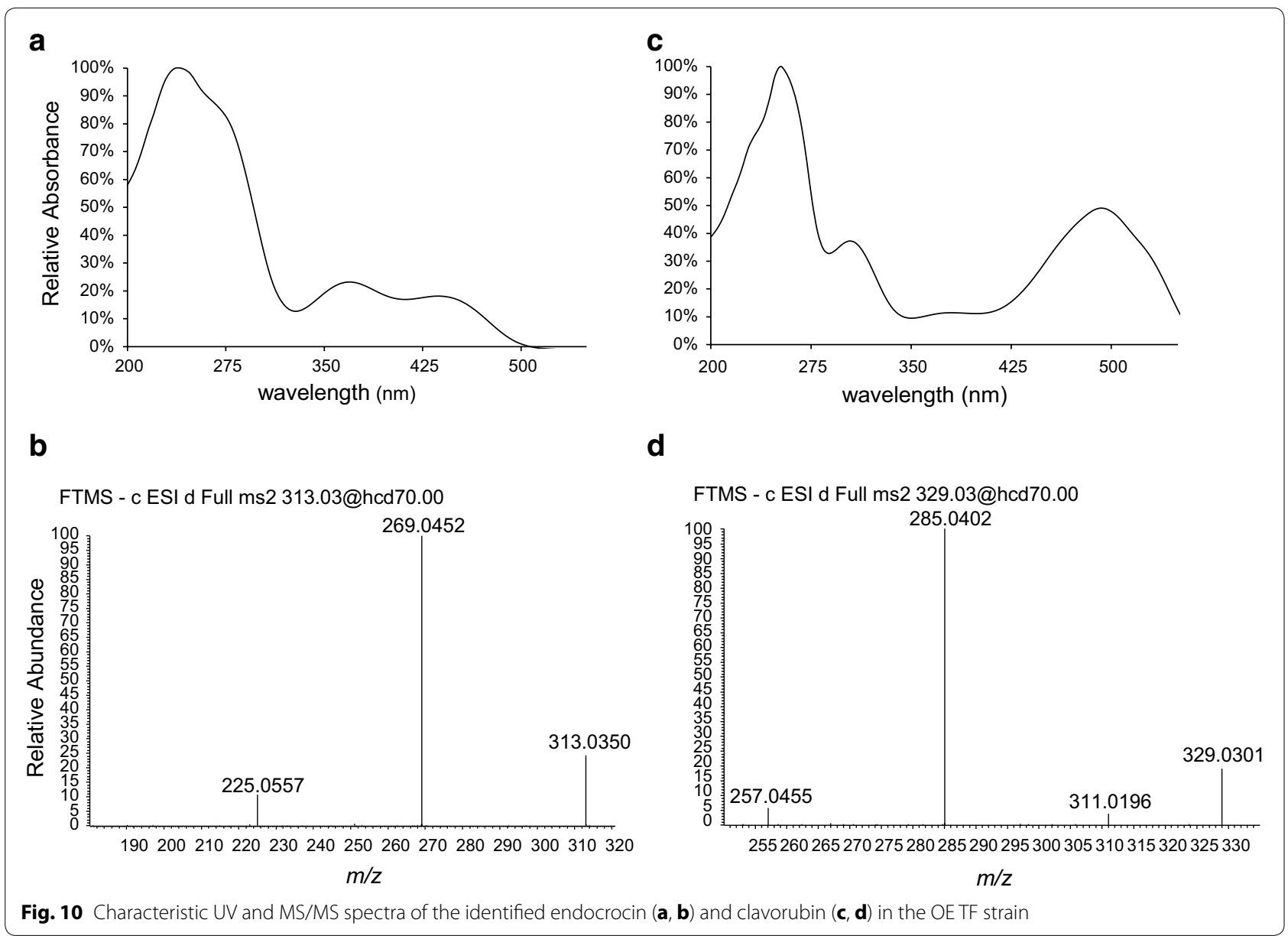

a

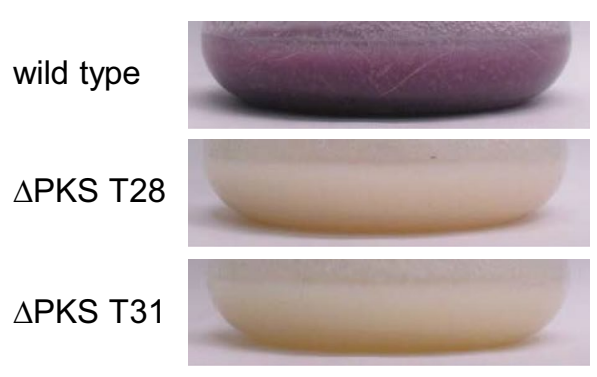

b

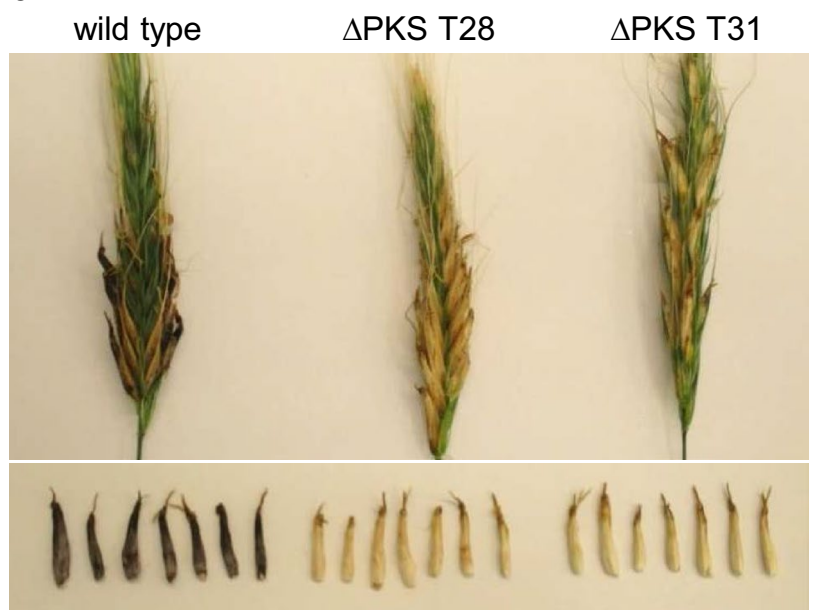

Fig. 11 Knock out of the PKS leads to a loss of pigmentation. a The C. purpurea wild type as well as the two $\triangle P K S$ mutants T28 and T31 were grown for 10 days in liquid media containing $100 \mathrm{~g} / \mathrm{L}$ sucrose and $4 \mathrm{~g} / \mathrm{L} \mathrm{KH}_{2} \mathrm{PO}_{4}$. b Rye plants were infected with the C. purpurea wild type as well as the $\triangle P K S$ mutants T28 and T31. Pictures were taken 5 weeks post-infection 


\section{a}

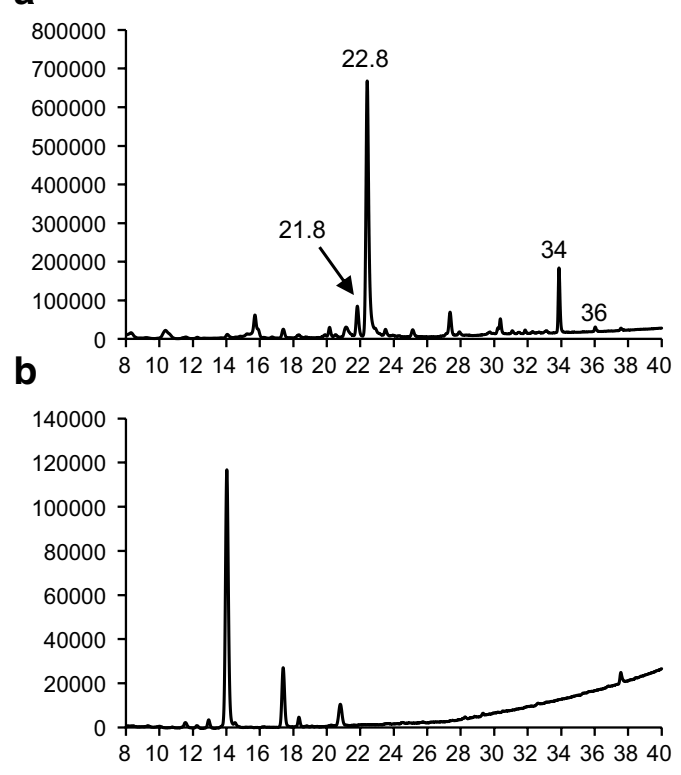

C
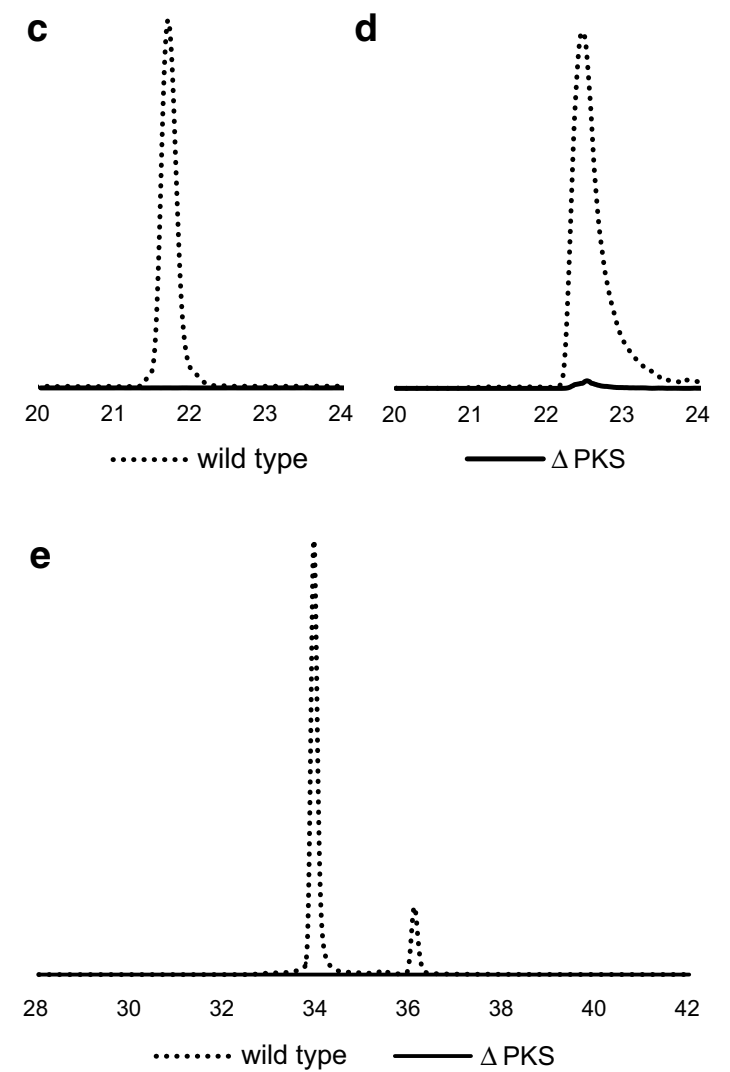

Fig. 12 HPLC-DAD profiles of the wild type (a) and $\triangle P K S$ (b) strain, as well as the HPLC-MS profile comparison of endocrocin (c), clavorubin (d) and secalonic acid (e) between the wild type and $\triangle \mathrm{PKS}$ strain. Strains were grown under conditions favorable for the pigment production. The relative difference between the mass spectrometric signal intensity is represented. The peaks in (a) are endocrocin (21.8 min), clavorubin (22.8 $\mathrm{min}$ ) and two secalonic acid derivatives with a retention time of 34 and $36 \mathrm{~min}$
Nevertheless, phosphate seems to be an important factor influencing the secondary metabolism of C. purpurea. As the alkaloid biosynthesis [30], the pigment biosynthesis is regulated by phosphate on a transcriptional level, but the molecular mechanism is still unknown. Generally, only little is known about the phosphate control of secondary metabolism. There are some examples that high concentrations of phosphate interfere with secondary metabolism of microorganisms [31]. Inorganic phosphate affects enzyme activities such as kinases and phosphatases, directly required in secondary metabolite biosynthesis or involved in signal transduction cascades, regulating e.g. fungal development, differentiation and other processes $[32,33]$. Usually secondary metabolite production is repressed by high levels of phosphate like the production of the antifungal protein (AFP) by Aspergillus giganteus [34], the production of bikaverin by Fusarium oxysporum [35] or the aflatoxin production Aspergillus parasiticus. To our knowledge, the pigment cluster in C. purpurea is the first fungal secondary metabolite cluster which is induced by high levels of phosphate.

Interestingly, there are also differences when you compare between the expression levels of the cluster genes in the wild-type under inducing conditions (Fig. 5a) and the OE_TF strain under non-inducing culture conditions (Fig. 5b). The key gene, the PKS CPUR_5437 is highly expressed in both strains. However, some cluster genes like CPUR_5431, CPUR_5434 or CPUR_5435 show a considerable higher expression in the wild-type under inducing conditions than in the OE_TF strain under noninducing conditions. Regulation of secondary metabolite clusters usually occurs on several levels. These results might indicate that at least for some of the pigment cluster genes, regulation by the culture conditions occurs on a higher level than the regulation by the transcription factor. However, it should be taken into account that Northern blots in Fig. 5a, b are two different experiments and therefore cannot be directly compared.

Several classes of fungal pigments are described including carotenoids, melanins, flavins, and quinones [36, 37]. C. purpurea produces two groups of yellow to red pigments: anthraquinonecarboxylic acids and dimeric hydroxanthone derivatives. Several fungi are able to produce anthraquinone pigments, either as cluster end products or as intermediates or shunt products. In $A$. fumigatus, for example, endocrocin is a product of two different gene clusters [17, 19]. Ergochromes have also been isolated from other fungi [38] but no corresponding gene clusters have yet been characterized. First reported were the ergochromes in C. purpurea [39]. In the 1960s the structures of the ergot pigments, as well as of several intermediates of their biosynthesis, have been largely established [8]. Here we report on the pigment 
gene cluster in $C$. purpurea for the first time and show that both groups of ergot pigments are products of the same biosynthetic pathway. Based on these results, the knowledge about pathway intermediates [8] and on comparison to similar characterized biosynthetic pathways $[12,17,19]$ a tentative biosynthetic pathway of the ergot pigments is proposed (Fig. 13).

Most likely endocrocin and clavorubin are shunt products in the pathway of xanthone biosynthesis. In the next steps dimerization of different xanthone units would lead to the formation of ergochromes. Genes CPUR_05425, CPUR_05426 and CPUR_05431 are unique to Claviceps in comparison to the $A$. nidulans xanthone cluster. Thus it is likely that these genes are involved in further modification of xanthone units or in their dimerization. Moreover, the metabolite profile of the OE TF strain (Fig. 7) shows several new peaks where the corresponding $\mathrm{m} / \mathrm{z}$ value does not fit with any known metabolite. Further investigations of these peaks may lead to the discovery of so far unknown ergochromes of C. purpurea.

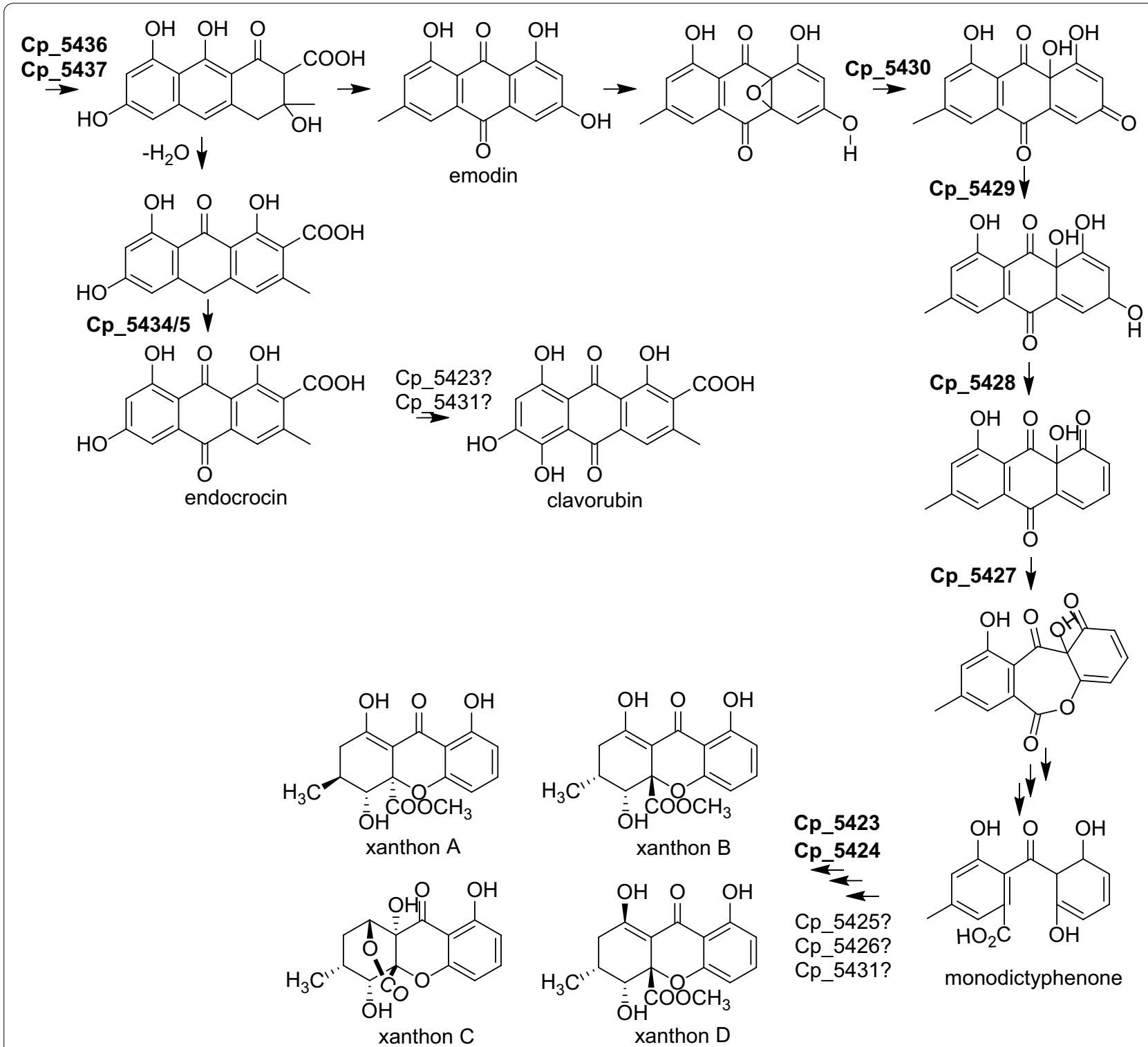

Fig. 13 Proposed biosynthetic pathway of ergot pigments. The xanthone units of the yellow ergochromes and the red anthraquinone pigments endocrocin and clavorubin are products from the same PKS derived precursors. The PKS gene was deleted in this study, assignment of roles for all other enzymes in bold were made based on comparison to similar characterized biosynthetic pathways [12, 13, 19]. Roles for enzymes in regular font are due to the predicted function of the corresponding gene (Table 1) 
Another interesting aspect is that single overexpression of the cluster key gene, the PKS CPUR_5437, is sufficient to induce production of the red anthraquinone pigments. As the cluster is not completely silent under these culture conditions, the expression level of the other cluster genes seems to be enough for the production of the simple pigments endocrocin and clavorubin but not for the complex structures of the ergochromes. It also might be that the increased through-put of the first pathway intermediate leads to a feedback loop and an up-regulation of other pathway genes.

Activation of the pigment cluster in axenic culture opens up new possibilities for uncovering the full biosynthetic pathway and for genetic engineering of the metabolic pathway to improve pigment production, or even to obtain modified molecules with novel bioactivity. Pigments are used as dyes for textiles, in cosmetics and as food colorants. Anthraquinone pigments, like the ones produce by $C$. purpurea, have several advantages; for example, they are relatively stable and have good light-fastness and brightness [40]. There is increasing commercial interest in the production of pigments by filamentous fungi as sources of cheaper, more ecologically friendly alternatives to existing dyes. Thus fungal pigment synthesis has several advantages over chemical methods [36, 41]. Besides their role as colorants, there is also a pharmaceutical value of ergot pigments, especially of the ergochromes. Ergoflavin, for example, has antiinflammatory and anticancer properties [10]. Secalonic acid A shows cytostatic and anti-tumor activity [9] and, additionally, has a neuroprotective effect, making it to an interesting possibility for the treatment of neurodegenerative diseases [11].

\section{Conclusions}

This study reports the identification and characterization of the ergot pigment gene cluster in C. purpurea. This gene cluster has been shown to be responsible for the typical purple-black color of ergot sclerotia but is not required for pathogenicity of the fungus. Furthermore, knock out of the pathway key enzyme, a NR-PKS, finally proved that both groups of ergot pigments, the red anthraquinonecarboxylic acids and the yellow ergochromes, are products of the same biosynthetic pathway. Fungal pigments gain increasing interest as ecologically friendly dyes or for the development of new pharmaceuticals. Activation of the C. purpurea pigment gene cluster in axenic culture and optimization of the culture conditions opens up new possibilities for biotechnological applications.

\section{Methods}

\section{Strains and culture conditions}

Claviceps purpurea strain Ecc93 has been described previously [42]. Mycelia were grown on BII medium [43] for maintenance and DNA isolation or on Mantle medium for conidia harvesting [44]. For secondary metabolite production strains were cultivated on a rotary shaker at $26{ }^{\circ} \mathrm{C}$ in modified media according to Amici [45] with sucrose and $\mathrm{PO}_{4}$ concentrations as indicated.

Yeast strains FY834 [46] used for the yeast recombinational cloning method were incubated at $30{ }^{\circ} \mathrm{C}$ in yeast extract-peptone-dextrose (YPD) or in synthetic dextrose (SD) medium lacking the selecting amino acids.

\section{Chemical and materials}

All chemicals were purchased from Sigma-Aldrich GmbH (Seelze, Germany), Carl Roth GmbH + Co. KG (Karlsruhe, Germany), or VWR International GmbH (Darmstadt, Germany). Solvents were obtained in gradient grade quality. Water for HPLC was purified by a Milli-Q Gradient A 10 system (Millipore, Schwalbach, Germany).

\section{Nucleic acid extraction and analysis}

Genomic DNA from C. purpurea was isolated as described by Cenis [47]. For Southern blot analysis, $5-10 \mu \mathrm{g}$ of digested genomic DNA were separated via gel electrophoresis in a $1 \%$ agarose gel with salt-free buffer [47] and transferred to a nylon membrane (Nytran SPC; Whatman). For the isolation of RNA, the RNAgents total RNA isolation kit (Promega GmbH, Mannheim, Germany) was used. For northern blotting, $20 \mathrm{mg}$ RNA were used for the separation on a $1 \%(\mathrm{w} / \mathrm{v})$ agarose gel containing $1 \%(\mathrm{v} / \mathrm{v})$ formaldehyde and afterwards transferred to a nylon membrane (Nytran SPC; Whatman). For southern as well as northern hybridization, 32P-labeled probes were generated using the random oligomerprimer method, and hybridized to the membranes. PCR reactions were performed using either the BioTherm Taq DNA Polymerase (GeneCraft, Germany) or the proof reading Phusion DNA polymerase (Finnzymes, Finland). Primers were synthesized by Biolegio (Nijmegen, Netherlands).

\section{Vector construction}

Vectors were constructed using the yeast recombinational cloning method [48], based on the described vector system $[49,50]$. The sequences of all primers used are listed in Additional file 4: Table S1. For construction of the $c p 5433$ overexpression vector, the $c p 5433$ gene was 
amplified with Phusion polymerase with the primers $\mathrm{OE}_{-}$ Cp5433_F and OE_Cp5433_R from genomic DNA and recombined with the NotI-NcoI-digested pNAH-OGG vector [50]. For construction of the cp5437 overexpression vector, the gene cp5437 was amplified with the primers OE_PKS4_F and OE_PKS4_R1 and OE_PKS4_F1 and OE_PKS4_R from genomic DNA using Phusion polymerase and recombined with the NotI-NcoI-digested pNAHOGG vector [50].

For construction of the cp5437 replacement vector, the flanking regions of $c p 5437$ were amplified with the primers PKS4_5F and PKS4_5R for the 5' flank as well as PKS4_3F and PKS4_3R for the $3^{\prime}$ flank. Primers contain overlapping sequences toward the yeast shuttle-vector pRS426 or the phleomycin resistance cassette. The phleomycin resistance cassette was amplified with the primers CpBle1F and CpBle1R from pRS426CpBle. The yeast shuttle vector pRS426 [48] was linearized by restriction with XhoI and EcoRI.

For homologous recombination the vector fragments were transformed into yeast strain FY834. The resulting vectors were selected on SD medium lacking uracil. DNA was isolated from yeast cells using the SpeedPrep yeast plasmid isolation kit (DualSystems) and transformed into Escherichia coli TOP10' for amplification.

\section{Fungal transformation}

Protoplasts of $C$. purpurea were generated with lysing enzymes from Trichoderma harzianum (Sigma-Aldrich, St. Louis) and transformed with $10 \mu \mathrm{g}$ of vector DNA as described by Jungehülsing et al. [51]. For selection, either phleomycin was directly applied to the protoplasts $(33 \mu \mathrm{g} / \mathrm{mL})$ or hygromycin was applied to regenerated protoplasts $24 \mathrm{~h}$ after transformation by overlay agar $(1.5 \mathrm{mg} / \mathrm{mL})$. Resistant colonies were transferred to fresh selective medium (BII, $\mathrm{pH} 8,100 \mu \mathrm{g} / \mathrm{mL}$ phleomycin or $0.5 \mathrm{mg} / \mathrm{mL}$ hygromycin). By PCR using specific primers as indicated, resistant transformants were checked for the integration of the vector.

\section{Pathogenicity assays}

Male sterile rye plants (Secale cereale) were cultivated in growth chambers as described by Smit and Tudzynski [52]. Florets of blooming ears (30-40 florets per ear) were inoculated with $5 \mu \mathrm{L}$ of a suspension containing $2 \times 10^{6}$ conidia $/ \mathrm{mL}$ as described by Tenberge et al. [53]. Afterwards, the ears were covered with paper bags equipped with cellophane windows to avoid cross contamination.

\section{qRT-PCR}

For reverse transcription of the RNA template, Superscript II reverse transcriptase (Invitrogen, Darmstadt,
Germany) was used. Real-time qPCR reactions were performed with the Bio-Rad iQ SYBR Green Supermix and the iCycler Thermal Cycler (Bio-Rad, Hercules, CA, USA). iCycler iQ Real-Time Detection System Software (version 3.0; Bio-Rad) was used for programming, data collection, and analyses. Expression of cp5436 was detected by the primers RTq_LN4_F and RTq_LN4_R and normalized to the expression of the housekeeping genes $\beta$-tubulin (CCE34429.1), $\gamma$-actin (AEI72275.1), and glyceraldehyde-3-phosphate dehydrogenase (X73282.1) [27] using primers Actin_uni and Actin_rev, Tub_uni and Tub_rev, and Gpd_uni and Gpd_rev.

\section{Analysis of fungal mycelium}

The mycelium was extracted with a mixture of acidified ethyl acetate and water. Water $(3 \mathrm{~mL})$ and of organic solvent $(4 \mathrm{~mL})$ were added to the mycelia in a $15 \mathrm{~mL}$ tube and shaken for $45 \mathrm{~min}$. In the next step, phases were separated and the organic solvent evaporated under nitrogen at $30{ }^{\circ} \mathrm{C}$. Residue was dissolved in $700 \mu \mathrm{L}$ acetonitrile/ water $1 / 9(\mathrm{v} / \mathrm{v})$ and $15 \mu \mathrm{L}$ used for HPLC injection.

\section{RP-HPLC-DAD-HRMS measurements}

In order to identify the pigments, the extracted mycelia were measured by RP-HPLC-DAD-HRMS. For the HRMS measurement, an Accela LC 60057-60010 system (Thermo Fisher Scientific, Bremen, Germany) was linked to a LTQ Orbitrap XL mass spectrometer (Thermo Fisher Scientific). A SPD-M20A Shimadzu PDA Detector (Shimadzu, Duisburg, Germany) was coupled to the MS spectrometer. Data acquisition was performed with Xcalibur 2.07 SP1 (Thermo Scientific). Separation was carried out on a $150 \times 2$ i.d., $3 \mu \mathrm{m}$, ReproSil-Pur C18-AQ (Dr. Maisch $\mathrm{GmbH}$, Amerbuch, Germany) using a binary gradient at a column temperature of $40{ }^{\circ} \mathrm{C}$. The injection volume was $15 \mu \mathrm{L}$ and the autosampler was cooled to $7{ }^{\circ} \mathrm{C}$. The flow rate was set to $260 \mu \mathrm{L} / \mathrm{min}$. Solvent A was acetonitrile with $0.1 \%$ of formic acid $(\mathrm{v} / \mathrm{v})$ and solvent B was water with $0.1 \%$ of formic acid (v/v). The HPLC was programmed as follows: in the first $4 \mathrm{~min}$ isocratic $15 \%$ of A, afterwards a binary gradient to $40 \%$ in $21 \mathrm{~min}$ and next during 16 min up to $100 \%$ of $\mathrm{A}$. Then the column was washed with $100 \% \mathrm{~A}$ and equilibrated at starting conditions. For the detection of the expected pigments a total ion scan of a mass range from $\mathrm{m} / z$ 165-950 with a resolution of 60,000 in the negative ion mode was used. To confirm the substances, subsequent mass spectrometric fragmentation experiments in the negative mode were used. The experiments included high-energy collision dissociation (HCD) with a relative energy of $40-85 \%$, depending on the ionization and an isolation width of $\mathrm{m} / z 1.5$ with and activation time of $30 \mathrm{~ms}$. The fragments 
were analyzed with the Orbitrap detector at a resolution of 30,000 .

\section{Mass spectrometer and DAD parameters}

The LTQ Orbitrap XL was used with a heated electrospray ionization technique. The sheat gas flow was 30 arbitrary units, the aux gas flow 15 arbitrary units and the sweep gas flow 10 arbitrary units. In the negative mode, vaporizer temperature was set to $300{ }^{\circ} \mathrm{C}$ and capillary temperature to $270{ }^{\circ} \mathrm{C}$. The source voltage was $3.0 \mathrm{kV}$, capillary voltage $-33 \mathrm{~V}$ and Tube Lens $-160 \mathrm{~V}$.

The Shimadzu PDA-Detector had the following parameters: starting wavelength $200 \mathrm{~nm}$, ending wavelength $700 \mathrm{~nm}$, with a wavelength step of $4 \mathrm{~nm}$. The sampling frequency was consequently $4.16 \mathrm{~Hz}$.

\section{Availability of supporting data}

The data sets supporting the results of this article are included within the article and its additional files. Gene sequences are available online: http://pedant.gsf.de/ pedant3htmlview/pedant3view?Method $=$ analysis $\& \mathrm{Db}=$ p3_p76493_Cla_purpu.

\section{Additional files}

Additional file 1: Figure S1. Generation of Cpur_05433 and Cpur_05437 overexpression mutants.

Additional file 1: Figure S2. Generation of Cpur_05437 knock out mutants.

Additional file 1: Figure S3. Complementation of the Cpur_05437 knock out.

Additional file 4: Table S1. Oligonucleotide primers used in this study.

\section{Authors' contributions}

LN, JD, H-UH, PT: conceptualization and methodology; LN: generation and analyses of mutants, gene expression studies; JD: HPLC-MS measurements; LN, JD: writing the manuscript, LN, JD, H-UH, PT: review and editing; PT, H-UH funding acquisition, resources and supervision. All authors read and approved the final manuscript.

\section{Author details}

${ }^{1}$ Institute of Plant Biology and Biotechnology, Westfälische WilhelmsUniversität Münster, Schlossplatz 8, 48143 Münster, Germany. ${ }^{2}$ Institute of Food Chemistry, Westfälische Wilhelms-Universität Münster, Corrensstr. 45, 48149 Münster, Germany.

\section{Acknowledgements}

We thank the Deutsche Forschungsgemeinschaft (DFG) for funding (Grants Tu50/18-1 and Hu730/11-1) and Peter G. Mantle for critical reading of the manuscript.

\section{Competing interests}

The authors declare that they have no competing interests.

Received: 21 December 2015 Accepted: 16 February 2016 Published online: 22 March 2016

\section{References}

1. Bove FJ. The story of ergot. Basle: S. Karger; 1970.

2. Shaw BI, Mantle P. Host infection by Claviceps purpurea. Trans Br Mycol Soc. 1980;75(1):77-90.

3. Luttrell E. Host-parasite relationships and development of the ergot sclerotium in Claviceps purpurea. Can J Bot. 1980;58(8):942-58.

4. Tudzynski P, Neubauer L. Ergot alkaloids. In: Martín JF, García-Estrada C, Zeilinger S, editors. Biosynthesis and molecular genetics of fungal secondary metabolites. New York: Springer; 2014. p. 303-16.

5. Buchta M, Cvak L. Ergot alkaloids and other metabolites of the genus Claviceps. Ergot, the genus Claviceps. Med Aromat Plants. 1999;6:173-200.

6. Franck B, Reschke T. Mutterkorn-Farbstoffe, II. Isolierung der hydroxyanthrachinon-carbonsäuren Endocrocin und Clavorubin aus Roggenmutterkorn. Chem Ber. 1960;93(2):347-56.

7. Franck B, Baumann G, Ohnsorge U. Ergochrome, eine ungewöhnlich vollständige Gruppe dimerer Farbstoffe aus Claviceps purpurea. Tetrahedron Lett. 1965;6(25):2031-7.

8. Franck B. Structure and biosynthesis of the ergot pigments. Angew Chem Int Ed Engl. 1969;8(4):251-60.

9. Kurobane I, Iwahashi S, Fukuda A. Cytostatic activity of naturally isolated isomers of secalonic acids and their chemically rearranged dimers. Drugs Exp Clin Res. 1987;13(6):339-44.

10. Deshmukh SK, Mishra PD, Kulkarni-Almeida A, Verekar S, Sahoo MR, Periyasamy $\mathrm{G}$, et al. Anti-inflammatory and anticancer activity of ergoflavin isolated from an endophytic fungus. Chem Biodivers. 2009;6(5):784-9.

11. Zhai A, Zhu X, Wang X, Chen $\mathrm{R}$, Wang H. Secalonic acid A protects dopaminergic neurons from 1-methyl-4-phenylpyridinium (MPP)-induced cell death via the mitochondrial apoptotic pathway. Eur J Pharmacol. 2013;713(1):58-67.

12. Chiang YM, Szewczyk E, Davidson AD, Entwistle R, Keller NP, Wang CC, Oakley BR. Characterization of the Aspergillus nidulans monodictyphenone gene cluster. Appl Environ Microbiol. 2010;76(7):2067-74.

13. Sanchez JF, Entwistle R, Hung JH, Yaegashi J, Jain S, Chiang YM, et al. Genome-based deletion analysis reveals the prenyl xanthone biosynthesis pathway in Aspergillus nidulans. J Am Chem Soc. 2011;133(11):4010-7.

14. Gatenbeck S. The occurrence of endocrocin in Penicillium-islandicum. Acta Chem Scand. 1959;13(2):386-7.

15. Räisänen R, Björk H, Hynninen PH. Two-dimensional TLC separation and mass spectrometric identification of anthraquinones isolated from the fungus Dermocybe sanguinea. Zeitschrift für Naturforschung C. 2000;55(3-4):195-202.

16. Kurobane I, Vining LC. MCINNES AG. Biosynthetic relationships among the secalonic acids. Isolation of emodin, endocrocin and secalonic acids from Pyrenochaeta terrestris and Aspergillus aculeatus. J Antibiot. 1979;32(12):1256-66.

17. Lim FY, Hou Y, Chen Y, Oh JH, Lee I, Bugni TS, Keller NP. Genome-based cluster deletion reveals an endocrocin biosynthetic pathway in Aspergillus fumigatus. Appl Environ Microbiol. 2012;78(12):4117-25.

18. Awakawa T, Yokota K, Funa N, Doia F, Mori N, Watanabe H, Horinouchi S. Physically discrete $\beta$-lactamase-type thioesterase catalyzes product release in atrochrysone synthesis by iterative type I polyketide synthase. Chem Biol. 2009;16(6):613-23.

19. Throckmorton K, Lim FY, Kontoyiannis DP, Zheng W, Keller NP. Redundant synthesis of a conidial polyketide by two distinct secondary metabolite clusters in Aspergillus fumigatus. Environ Microbiol. 2016;18(1):246-59.

20. Nielsen MT, Nielsen JB, Anyaogu DC, Holm DK, Nielsen KF, Larsen TO, Mortensen UH. Heterologous reconstitution of the intact geodin gene cluster in Aspergillus nidulans through a simple and versatile PCR based approach. PLOS ONE. 2013;8(8):e72871.

21. Schardl CL, Young CA, Hesse U, Amyotte SG, Andreeva K, Calie PJ, Fleetwood DJ, Haws DC, Moore N, Oeser B. Plant-symbiotic fungi as chemical engineers: multi-genome analysis of the Clavicipitaceae reveals dynamics of alkaloid loci. PLoS Genet. 2013;9(2):e1003323.

22. Aberhart D, Chen Y, De Mayo P, Stothers J. Mould metabolites-IV: the isolation and constitution of some ergot pigments. Tetrahedron. 1965;21(6):1417-32.

23. von Bargen C, Hübner F, Cramer B, Rzeppa S, Humpf H. Systematic approach for structure elucidation of polyphenolic compounds using a bottom-up approach combining ion trap experiments and accurate mass measurements. J Agric Food Chem. 2012;60(45):11274-82. 
24. Kawamura C, Tsujimoto T, Tsuge T. Targeted disruption of a melanin biosynthesis gene affects conidial development and UV tolerance in the Japanese pear pathotype of Alternaria alternata. Mol Plant Microbe Interact. 1999;12(1):59-63.

25. Cary JW, Harris-Coward PY, Ehrlich KC, Di Mavungu JD, Malysheva SV, De Saeger $S$, et al. Functional characterization of a veA-dependent polyketide synthase gene in Aspergillus flavus necessary for the synthesis of asparasone, a sclerotium-specific pigment. Fungal Genet Biol. 2014;64:25-35.

26. Liu GY, Nizet V. Color me bad: microbial pigments as virulence factors. Trends Microbiol. 2009;17(9):406-13.

27. Giesbert S, Schuerg T, Scheele S, Tudzynski P. The NADPH oxidase Cpnox1 is required for full pathogenicity of the ergot fungus Claviceps purpurea. Mol Plant Pathol. 2008;9(3):317-27.

28. Schürmann J, Buttermann D, Herrmann A, Giesbert S, Tudzynski P. Molecular characterization of the NADPH oxidase complex in the ergot fungus Claviceps purpurea: CpNox2 and CpPIs1 are important for a balanced host-pathogen interaction. Mol Plant Microbe Interact. 2013;26(10):1151-64.

29. Taber W. Biology of Claviceps. In Demain AL, Nadine AS, editors. Biology of industrial microorganisms. Biotechnology series, vol 6. New York: The Benjamin Cummings Publishing Co Inc. 1986; p. 449-86.

30. Haarmann T, Machado C, Lubbe Y, Correia T, Schardl CL, Panaccione DG, Tudzynski P. The ergot alkaloid gene cluster in Claviceps purpurea: extension of the cluster sequence and intra species evolution. Phytochemistry. 2005;66(11):1312-20.

31. Sanchez S, Demain AL. Metabolic regulation of fermentation processes. Enzyme Microb Technol. 2002;31(7):895-906.

32. Krebs EG, Beavo JA. Phosphorylation-dephosphorylation of enzymes. Annu Rev Biochem. 1979;48(1):923-59.

33. Lengeler KB, Davidson RC, D'souza C, Harashima T, Shen WC, Wang P, et al. Signal transduction cascades regulating fungal development and virulence. Microbiol Mol Biol Rev. 2000;64(4):746-85.

34. Meyer $V$, Stahl U. New insights in the regulation of the afp gene encoding the antifungal protein of Aspergillus giganteus. Curr Genet. 2002;42(1):36-42.

35. Brewer D, Arsenault G, Wright J, Vining L. Production of bikaverin by Fusarium oxysporum and its identity with lycopersin. J Antibiot. 1973;26(12):778-81

36. Dufosse L, Fouillaud M, Caro Y, Mapari SA, Sutthiwong N. Filamentous fungi are large-scale producers of pigments and colorants for the food industry. Curr Opin Biotechnol. 2014;26:56-61.

37. da Costa Souza PN, Grigoletto TLB, de Moraes LAB, Abreu LM, Guimarães LHS, Santos C, Galvão LR, Cardoso PG. Production and chemical characterization of pigments in filamentous fungi. Microbiology. 2016;162:12-22.

38. Masters K, Bräse S. Xanthones from fungi, lichens, and bacteria: the natural products and their synthesis. Chem Rev. 2012;112(7):3717-76.
39. Kraft F. Über das Mutterkorn. Arch Pharm (Weinheim) 1906;244(4-5):336-59.

40. Caro Y, Anamale L, Fouillaud M, Laurent P, Petit T, Dufosse L. Natural hydroxyanthraquinoid pigments as potent food grade colorants: an overview. Nat Prod Bioprospect. 2012;2(5):174-93.

41. Duran N, Teixeira MF, De Conti R, Esposito E. Ecological-friendly pigments from fungi. Crit Rev Food Sci Nutr. 2002;42(1):53-66.

42. Keller U, Han M, Stoeffler-Meilicke M. D-Lysergic acid activation and cellfree synthesis of D-lysergyl peptides in an enzyme fraction from the ergot fungus Claviceps purpurea. Biochemistry (N Y). 1988;27(16):6164-70.

43. Esser K, Tudzynski P. Genetics of the ergot fungus Claviceps purpurea. Theor Appl Genet. 1978;53(4):145-9.

44. Mantle PG, Nisbet LJ. Differentiation of Claviceps purpurea in axenic culture. J Gen Microbiol. 1976;93(2):321-34.

45. Amici A, Minghetti A, Scotti T, Spalla C, Tognoli L. Production of ergotamine by a strain of Claviceps purpurea (Fr.) Tul. Experientia. 1966;22(6):415-6.

46. Winston F, Dollard C, Ricupero-Hovasse SL. Construction of a set of convenient Saccharomyces cerevisiae strains that are isogenic to S288C. Yeast. 1995;11(1):53-5.

47. Cenis JL. Rapid extraction of fungal DNA for PCR amplification. Nucleic Acids Res. 1992;20(9):2380

48. Colot HV, Park G, Turner GE, Ringelberg C, Crew CM, Litvinkova L, et al. A high-throughput gene knockout procedure for Neurospora reveals functions for multiple transcription factors. Proc Natl Acad Sci USA. 2006;103(27):10352-7.

49. Christianson TW, Sikorski RS, Dante M, Shero JH, Hieter P. Multifunctional yeast high-copy-number shuttle vectors. Gene. 1992;110(1):119-22.

50. Schumacher J. Tools for Botrytis cinerea: new expression vectors make the gray mold fungus more accessible to cell biology approaches. Fungal Genet Biol. 2012;49(6):483-97.

51. Jungehülsing U, Arntz C, Smit R, Tudzynski P. The Claviceps purpurea glyceraldehyde-3-phosphate dehydrogenase gene: cloning, characterization, and use for the improvement of a dominant selection system. Curr Genet. 1994:25(2):101-6.

52. Smit R, Tudzynski P. Efficient transformation of Claviceps purpurea using pyrimidine auxotrophic mutants: cloning of the OMP decarboxylase gene. Mol Gen Genet. 1992;234(2):297-305.

53. Tenberge KB, Homann V, Oeser B, Tudzynski P. Structure and expression of two polygalacturonase genes of Claviceps purpurea oriented in tandem and cytological evidence for pectinolytic enzyme activity during infection of rye. Phytopathology. 1996;86(10):1084-97.

54. Dereeper A, Guignon V, Blanc G, Audic S, Buffet S, Chevenet F, et al. Phylogeny.fr: robust phylogenetic analysis for the non-specialist. Nucleic Acids Res. 2008;36:465-9.

\section{Submit your next manuscript to BioMed Central and we will help you at every step:}

- We accept pre-submission inquiries

- Our selector tool helps you to find the most relevant journal

- We provide round the clock customer support

- Convenient online submission

- Thorough peer review

- Inclusion in PubMed and all major indexing services

- Maximum visibility for your research

Submit your manuscript at www.biomedcentral.com/submit
() Biomed Central 